\title{
MOBILITY IN THE ROUND: Use of Wireless Laptop PCs in Clinical Ward Rounds
}

\author{
Henrique M. G. Martins \\ Matthew R. Jones \\ Judge Institute of Management \\ University of Cambridge \\ Cambridge, $U K$
}

\begin{abstract}
It has been suggested that mobile information and communication technologies (MICTs) are better suited than traditional desktop devices to support work practices where participants are either moving around or conduct their work in different spatially dispersed settings. One such practice, which might be expected to benefit from MICT support, is the ward rounds conducted by hospital doctors. After a brief description of this practice, data are presented on the usage of laptop PCs in ward rounds in the Medicine Service of a U.S. hospital with a well-established IT infrastructure. Drawing on questionnaires, interviews, and observational evidence, the paper explores why, 5 years after the laptops were first introduced, a quarter of the clinicians had never used them, and only a quarter took advantage of more than their basic functionality. A number of possible reasons for the failure of doctors to adopt a technology that is seen as offering significant benefits to their work are discussed. In particular, it appeared that the reliability of the technology, differences in senior doctors' ward round practices, and social inertia contributed to the low level of uptake. Other local factors, such as the architecture

of the building and departmental practices regarding laptop usage, also affected doctors' use. Implications for research on ubiquitous computing are drawn.
\end{abstract}

\section{INTRODUCTION}

While the precise relationship between ubiquitous and mobile computing is a subject of continuing debate, in the aissence of genuinely pervasive computing resources in most work environments, mobile information communication technology (MICT) 
devices, especially when supported by wireless networks, offer a means of expanding the range of settings in which computation is accessible. This does, of course, provide only partial ubiquity (a contradiction in terms!), and the mobility of the device per se is not enough to ensure that computing resources are actually available, as this is likely to be dependent on the correct functioning of a variety of technical and social infrastructures, such as networks, power supplies, and work arrangements, that make device use practicable. Nevertheless, bringing computers to the work practice, rather than the work to computers, constitutes a new opportunity for supporting work that is carried out "on the move," or conducted in a number of spatially dispersed settings.

At least until recently, such settings have received little attention in the literature on ICT implementation, which has tended to focus on situations where desktop computing has been used to support static work practices (Zuboff 1987). The growing mobile computing literature (Esbjörnsson 2002; Esbjörnsson et al. 2002; Esbjörnsson and Östergren 2002), however, typically suggests that MICTs may be better suited to supporting such work practices than static/desktop devices, and hence, that the adoption of MICTs in such settings may be expected to lead to increased efficiency and effectiveness of these work practices.

One specific type of work that is seen as particularly mobile, and therefore likely to benefit from MICT support, is that of hospital doctors (Bardram et al. 2003), especially during their ward rounds. Studies of ward rounds (Atkinson 2001; Freeman and Reeder 1957; Martins and Jones forthcoming; Strauss et al. 1997) have identified them as serving a range of functions, such as gathering patient-related information, clinical decision-making, formulation of treatment plans and education. It is suggested (Cox 2002; Davis 2002; Kelly 2001) that MICTs may improve ward rounds by

- making available up-to-date patient data at the point of care, leading to more appropriate treatment

- allowing faster updating of treatment plans, leading to better treatment

- allowing access to reference information, leading to improved clinical decisionmaking and increased opportunities for learning

Indeed, there have been a number of largely self-reported accounts of the positive effect of such technology on clinical practice (Grasso and Genest 2001; Holleran et al. 2003).

It might, therefore, be expected that if MICTs were made available to doctors, they would use them in their ward rounds. Drawing on an in-depth study of the level and form of usage of MICTs by doctors working in the Medical Service of a large U.S. hospital that has provided wireless access to a comprehensive electronic medical record (EMR) and other resources for more than 5 years, this paper explores possible reasons why such expectations may not be realized. While the findings reported relate to the work practices of hospital doctors, a number of more generic features of support for mobile work practices are identified that may be relevant in other settings.

\section{WARD ROUNDS: A BRIEF INTRODUCTION}

Ward rounds, also known as clinical visits or simply rounds, are events when hospital doctors, as a team, typically comprising a senior doctor (Attending Physician), 
one or two junior doctors (Residents or Interns), and one or two medical students, visit the bedside of each inpatient under their care in turn. Such rounds are necessary because most inpatients are generally bed-bound.

Ward rounds can vary significantly (for example, in terms of their frequency, duration, and the personnel involved) depending on the particular clinical speciality, the clinical setting (wards or intensive care units), and also between countries. The following generic description, based on fieldwork from hospitals in the United States, United Kingdom, Singapore, and Portugal, summarizes some of the key features of ward rounds and helps to place later discussion in context.

The pre-round period, before the senior doctor arrives, can be quite hectic for junior doctors as they try to retrieve and aggregate as much information about patients as possible from the hospital computer systems (typically accessed via desktop computers) and/or paper files held in the doctor's office. To facilitate later recall, the junior doctors may take notes on pieces of paper that they carry in their pockets. The ward round typically starts with the arrival of the senior doctor and proceeds without preliminary discussion of patients. Rather, at each patient bed, a junior doctor (or sometimes a medical student) will be expected to present a summary of the condition and treatment of the patient (drawing, where appropriate, on the notes they may have taken earlier or paper records held at the bedside). Questions and discussion follow the presentation. At some point, the patient is also usually questioned about their condition and physical examinations may be conducted. This information is used by the team for a discussion, of variable duration, about the treatment plan for that patient. During this discussion, further questions may be posed to the patient and further data sought from existing records. Requests for information searches or for tasks to be executed after the ward round may be made at this time. Discussion is often not restricted to the specifics of the particular case, but will include broader medical discussion and teaching, and there can often be an exam-like interrogation of the junior doctors' and medical students' knowledge by the senior clinicians. The ward round normally ends with a plan of action (of varying specificity), which may include ordering of clinical investigations, further analysis of the case, changes to drug regime, or a decision to discharge the patient, all to be executed at a later stage. It is also customary that before the team moves on to the next patient, the senior doctor reminds the junior doctors of topics to study before the next ward round, and either only cordially says goodbye to the patient or does it after a very brief friendly chat.

A variant of the typical ward round, with potential implications for desktop and mobile ICT usage, is the "sitting ward round." In this case, the team often gathers not by the bedside but sitting in a room away from the patients. Each patient is discussed in turn, in more or less the same way, and a plan is often formulated. The team then leaves the room and visits all patients at their beds, in turn. At this stage, however, having already discussed the case, this visit generally serves as a chance for the team to see the patient and exchange some brief words, although sometimes there is some reopening of discussion of the case.

As this shows, ward rounds serve several functions including decision making about short term and long-term patient care, immediate plan formulation for diagnosis and treatment, education (both teaching and evaluative), patient contact and comforting, as well as team-building. In some departments, these tend to be crucial daily, biweekly, 
or weekly events as they are often the only occasion where the whole medical team caring for a group of patients is actually copresent.

Although, individually, doctors are increasingly reported to be using MICT devices such as handheld/PDAs (Barret et al. 2004; McLeod et al. 2003), predominantly as a source of medical or drug reference information, these are generally not connected to the hospital IT systems. Historically, ward rounds have also not been directly supported by ICTs (even if a complete EMR was available), as the EMR was typically only available via desktop computers. Sitting ward rounds, however, may be supported with desktop technology in some departments.

\section{METHODOLOGY}

The research reported in this paper forms part of a larger study covering ten sites in eight different hospitals in four countries (Portugal, United Kingdom, United States, and Singapore) carried out between December 2003 and December 2004, where observation, interviews, questionnaires, and data from log files was used to study doctors' and organizations' use of MICTs and technologies to support remote working.

\subsection{Case Selection}

The particular findings discussed in this paper derive from a study carried out in August 2004 at the Medical Service of the Veterans Affairs Medical Center, Washington, DC. This case was chosen because conditions there appear to be particularly favorable for MICT use: the hospital has a full EMR that, in the Medical Service, has been available for 7 or 8 years via desktop computers and for more than 5 years through wireless laptop PCs. With five similar medical teams using similar devices this case also enables differences in individual and group uptake of MICT to be explored.

\subsection{Methods}

Research was conducted using three data-gathering methods.

- Questionnaires about attitudes to, and usage of, desktop and mobile ICT were distributed and collected at regular department meetings, with 33 questionnaires (from a total of 36 collected).

- Participant observation was conducted on the department wards. Clinicians were accompanied during the course of the day, predominantly before and during their ward rounds, and this was often complemented with informal interviews.

- A program of semi-structured interviews was carried out with doctors working at the department. Interviews were held in a calm environment and taped with the participants' permission. Transcripts were coded to ensure confidentiality and anonymity. 
In all, 16 interviews were carried out, seven with Attendings (senior doctors) who had worked in the department during the last year, eight with junior doctors (Residents and Interns) working on the wards at the time of the study, and one with a medical student. In total, 13 hours of formal interviews and 75 hours of participant observation were conducted.

A grounded theory approach (Glaser and Strauss 1967) was used to identify emergent themes from the interviews and observation data as well as from open-ended answers in the questionnaire.

\section{CASE DESCRIPTION}

\subsection{The Department and its Wireless Laptops}

The VA Medical Center is a multispeciality tertiary care facility. At any given time there may be around 60 doctors working in the Medical Service, distributed between a 12-bed intensive care unit, wards (with 87 beds), or outpatient clinics. The MICT devices made available for ward rounds were (at the time of study) standard laptop PCs with WiFi wireless connection. These were attached to a food trolley (as illustrated in Figure 1) and could not be removed. The $\mathrm{AC}$ adapter was also attached with a conventional power cable that could be extended to only a nearby wall socket. No mouse or extra battery were attached.

This apparatus was only movable as a whole, but the height of the tray could be adjusted and there was some free space on the tray to the sides of the Laptop. Although the particular model of laptop used had changed over time, this set-up had

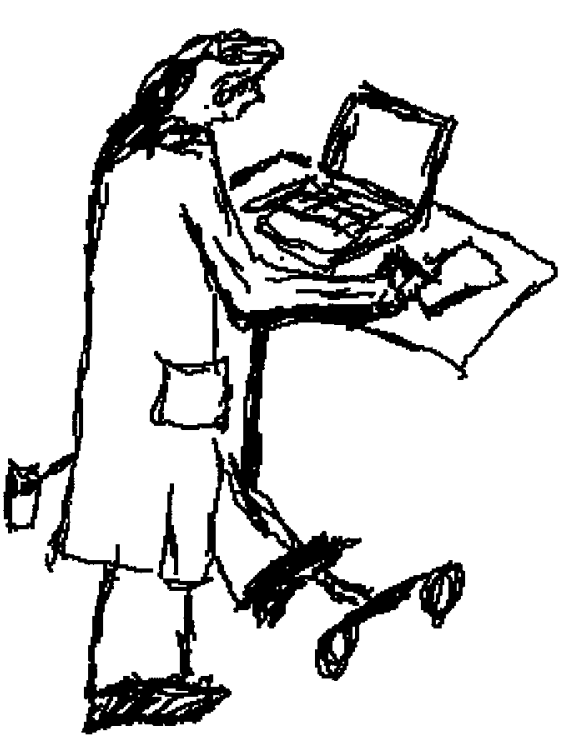

Figure 1. Sketch of the Resident from Team Beta Using the Wireless Laptop been constant. While recognizing that the food trolleys were not ideal, the Head of Department, explained that they had been used because funding for laptops did not include a budget for carts to hold them.

The laptops provide full access to Windows software, two hospital systems (a full EMR which includes the availability of all imaging studies and a drug administration system mostiy used by the nurses), and the Internet. The hospital has its own intranet resources (links to departments guidelines and protocols, library holdings, and online resources), and broadband access to the Internet through a network filter for some sites considered less appropriate. The department policy toward computer usage (desktop and laptop) was liberal. 
We've never told them not to [use Internet Explorer]....It's not that we had any constraints...you could do other things that you're not supposed to do either on them, and that has gotten people into trouble here (Head of Department).

Of the 33 staff studied, 24 were Attendings and 9 were Residents or Interns, with almost equal numbers of men and women. Less than half of the doctors owned a handheld/PDA. All doctors used a desktop every day for clinical work, 60 percent of them more than 10 times a day. Attending clinicians reported a higher frequency of use than Residents. The Internet was used for clinical work related with the department by all respondents at least once a week.

\subsection{Wireless Laptop Usage in the Department}

While two-thirds of the doctors had been using the wireless laptops for more than a year, almost a quarter (equally distributed between Attendings and Residents/Interns) claimed that they never used them and the remainder (mostly Residents/Interns) reported shorter periods of use.

About one-fifth of the doctors were high frequency users, using the laptops more than five times a day for clinical work, 35 percent were medium frequency users, while another fifth used them less than once a week (one-quarter were nonusers). All doctors used the laptops to check patient data, but only two for medical calculations and one to send clinical-related e-mails. No doctor reported using the laptops for checking hospital guidelines. The users thus comprised three groups: multi-task users, who browsed the Internet for medical information, checked medical and drug reference information, as well as consulting the EMR; standard users, who used the laptops only to access the EMR; and nonusers.

Age, gender, seniority, and usage of technologies other than MICTs showed no significant difference between the user group and the nonuser group. The multi-task user group reflected the seniority and gender make-up of the department, but included predominantly high- and medium-frequency users, most of whom owned a handheld/ PDA (compared to almost none of the other groups).

One distinctive aspect of the Medical Service was the high turnover of staff. Residents, Interns, and medical students joined the department on a 4-week rotation from nearby universities and hospitals (each with different EMR systems and ward layouts), while the Attendings typically covered the wards for 4 weeks per year. All the rotations occurred asynchronously, meaning that knowledge of EMR use had to be continuously replaced. Using the laptops during ward rounds was, thus, one of the few occasions when all team members were together as a group, and provided an important opportunity for Attendings to teach others about the operation and capabilities of the hospital's systems.

Another distinctive aspect of the Service was that most of its patients were located in wards on two consecutive floors of the hospital building. Each ward had a central area (with several desktop computers) from which six corridors of patient rooms lead off. Each floor had two or three doctors' rooms (with five desktop PCs). The floors were connected by service stairs, but the elevator was located away from the center of 
the wards. Normally teams had patients on both floors and doctors identified this layout as affecting their usage of laptops.

Each of the teams has a laptop, chained, nailed, spiked, or something to a portable table, which makes it quite cumbersome, by the way, because we tend to go up and down between the third and fourth floor and you have to carry the table with you or go use the elevators which are painfully slow (Resident, Team Alpha).

\subsection{Views of Nonusers}

One team of doctors in particular (Team Alpha) never used the laptop PCs during the observation period; instead the Resident wrote out file-cards with relevant data for each patient and updated this with new data and action plans during the ward round. The Interns also kept their own, paper-based notes. The Resident, who was a charismatic individual, seemed to be more influential than the Attending in this team. $\mathrm{He}$ often spoke on behalf of the team and seemed to have been responsible for the team's non-usage of the laptops.

Well I guess on rounds it's the Resident's call. We never even had that as an option (Intern, Team Alpha).

This was not because he was unaware of the potential benefits of MICT use on ward rounds, however.

It's quite unusual for all the labs that are of interest to be complete by the time we round. I suppose it would be nice to have that available, but we simply discuss our plan based upon what we have, we have some notion of what lab values are likely to change if there are going to be values that change, and so we usually can make most planning decisions ahead of time by giving criteria for what lab we expect (Resident, Team Alpha).

The Intern in the team did not use the wireless laptops at other times either. His reasons for this reflect issues raised by a number of other doctors on the ward.

If I'm pushing the laptop around, I can't use the stairs, I can't carry it with me, it's hooked up to that desk, and then you know if I'm running around back and forth between the nurses station and the patient rooms and going here and there, I find that when I'm walking around the wards I'm running all over the place so I don't want to have to be responsible...for the laptop, if it gets damaged or stolen or anything. So it's not really a benefit. And [there are] so many computers available anywhere I am, I'm no more than 5 or 10 seconds away from sitting down at a desktop and getting the information Ineed (Intern, Team Alpha). 
The Resident based his decision not to use the wireless laptops on his earlier experience working on a team where the devices were used daily.

Last year....Rounds tended to be more administratively frenetic when we had the laptop with us. There was more a temptation to do orders immediately, there was more waiting for lab results to come back and interrupting a chain of thought regarding the patient (Resident, Team Alpha).

Another concern was that laptops could affect education by reducing junior doctors' information processing capabilities and distracting their attention during the actual rounds.

I didn't want [the laptop] with us because I wanted folks on rounds to focus on the pieces of information that struck them as they were collecting it...The likelihood was [also] that there would be nothing more than one or two data points on a couple patients that we miss and that would be required for a decision at that point (Resident, Team Alpha).

The Resident felt very confident that ward rounds without the laptop were as good as those with it in almost every situation, although he identified one exception where the team was responsible for a large number of patients, including a significant number of patients from other teams.

During the observation period there were two Attendings covering the team, although laptops were not used with either. The second Attending had been working with the team for less than a week and, although she had previously used wireless laptops for ward rounds in her last job, perceived their use as valuable, she did not insist on their use in Team Alpha. This may have been because she was unfamiliar with the devices in the particular hospital.

I haven't actually seen them [but]I think [using laptops will] be a nice idea. We had them at Hopkins and we ended up using them a lot. They were fairly new... and I thought it was helpful on rounds to have information (Attending, Team Alpha).

\subsection{Views of Users}

The most active users at the time of the study were Team Beta, who had two laptops in their room, one of which served as a backup in case the first laptop failed. Even this team, however, did not always use laptops, as a medical student explained,

[With] the first Attending... we'd have more sit down rounds in our team room discussing things. So at that point we would be putting...the orders directly onto our desktops and then when we would round, we wouldn't really take the computer with us. The second Attending...would prefer us to have the computer with us but at that time we were having a lot of glitches with the com- 
puters. The last Attending we've had, again she seems to be more sit down, get things kind of under our grasp, and then go from there. Although we still take the laptop with us. But again taking the laptop with us helps just getting orders done quicker and as something comes up you can order it at that time, or looking again at radiology is useful (Medical Student, Team Beta).

Another of the team members explained the team's usage of the laptops as being due to a combination of junior and senior clinician styles.

If you have a team that... really likes to get things tucked away early in the day and doesn't like to wait for things that you could have at your fingertips like lab results and sort of come back as you round on the patients, then I think that the laptops would be utilized more. And that was our case...It was driven by the Resident and the Attending, sort of the tone and the pace, and it's my impression that other teams didn't have the same sort of drive (Intern, Team Beta).

Team Beta's enthusiasm for laptop use did not appear to be dimmed by the unreliability of the technology (a problem specifically highlighted in almost half the comments on the questionnaires). While the team showed frustration when their ward rounds were frequently disrupted by the laptop crashing or losing power, they generally tried to solve the problem while continuing their discussion. For example, the Attending would continue asking questions about the patient while rebooting the laptop or searching for a wall plug. Occasion-

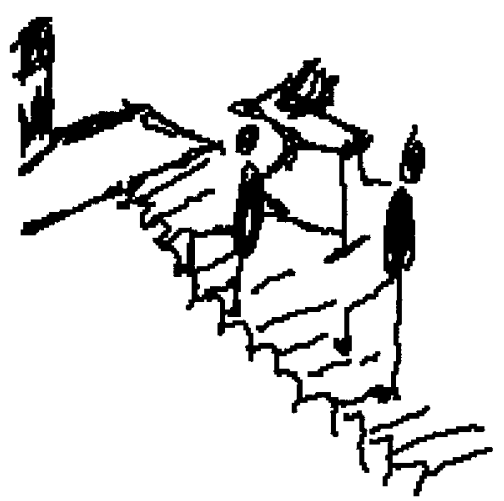

Figure 2. Sketch of Two Members of Team Beta Carrying the Laptop and Trolley Upstairs ally they would even have to conduct rounds without a laptop because both were not working. Again, however, the Attending responded to this by chasing the IT department for prompt maintenance.

I mean usually we go a couple of days and then something goes wrong. But that's been a constant. And everyday I'm going to a computer person going, they're not working again (Attending, Team Beta).

Team Beta were based predominantly on the upper floor, but would visit patients on the lower floor daily. Except for occasions when there were only a few patients to be visited, two of the male Interns or medical students would take hold of the trolley with the laptop and carry it downstairs. The elevator was never used, despite the problems with carrying the device (on its trolley) upstairs (see Figure 2). 
During the observation period, two Attendings covered the team. Both were enthusiastic about technology in general and the laptops in particular. As one of them put it,

And I guess depending on the attending some people just want to hear about the things...I am a data person. So I like the availability of data (Attending, Team Beta).

Because the hospital's systems also allowed remote access, both sometimes worked from home.

The main reason cited by members of Team Beta for use of the devices was that they increased team efficiency by allowing ready access to patient information and the input of at least some of the most urgent orders while rounding.

Because all of the orders are on the computer, it just makes things run smoother if during rounds you come up and say, I need this order done, rather than waiting 'til the end of rounds to do it, you know you can do it right there....The round's a lot more complete I think, also, much more efficient (Medical Student, Team Beta).

These benefits, however, were seen to depend on the team's capacity to work collaboratively. For example, orders would be entered, or the Resident would retrieve information with the laptop, while a patient was being presented by the Interns or medical students. Most team members were also in agreement about the advantages of being able to check the most up-to-date laboratory information.

When we come in and see the patients early in the morning, often times results are not there but by the time we round, almost certainly they are and that makes everything a lot easier because we can adjust issues (Intern, Team Beta).

Another common theme was the usefulness of the laptops as a support for additional information requests or to look at patterns of data from the patient's whole medical record.

The seven other Attendings working in the department mostly used the laptops for ward rounds because they liked to have easy access to data and immediate action like order entry. One Attending, in particular, saw this as giving him greater control.

I want up-to-date information, I want to see the information myself rather than relying on somebody else's recitation of it....And then of course I do want to be able to review all the medications and not only rely on what somebody tells me the patient's on. Because they sometimes are mistaken.... [and] I want to be able to implement whatever plan we 're concerned about immediately. I do not want to delay, I want to enter it into the system as we talk (Attending, Team Gamma).

Another Attending, in contrast, explained that she favoured laptop use because it encouraged a particular style of work and she saw it as better for education. 
It's largely to keep the tradition of walk ward rounds going despite the fact that we had technology that would otherwise tie us into that room.... without the laptop we would sit in the team room and talk about 12 or 15 patients, all in sequence, and then we'd go around and see everybody... The teaching was much stronger when we talked about patients as we went to see each one of them... and we weren't doing walk rounds before we had mobile laptops (Attending, Team Delta).

The same concern for education was voiced by an attending who was supportive of students retrieving data from online sources during rounds.

It's quite typical that while we're talking about this patient a student is looking up something on Up-to-Date. That happens frequently on rounds. They'll say, oh, Up-to-Date says, you know (Attending, Team Gamma).

\section{CASE ANALYSIS: ACCOUNTING FOR THE ADOPTION OF MICT IN WARD ROUNDS}

Contrary to claims in some of the literature (McLeod et al. 2003), age, gender, seniority, and usage of desktop technology do not seem to be related to laptop usage. Similarly, previous experience of MICT use for ward rounds did not always lead to greater uptake. Moreover, despite all teams being of a similar size, having access to a full EMR (both on desktops and on the laptop PCs, with the same application view) and ample desktop computing, about a quarter of the doctors claimed never to have used the laptops and three out of five teams were not using them at the time of study. It would seem, therefore, that some traditional explanations for the uptake of MICTs in ward rounds did not apply, at least in this setting.

In terms of reasons for non-usage of the laptops, unreliability of the technology was widely identified, although it is unclear whether this reflected significant technical problems (that might be overcome by future technological advances) or difficulties in establishing routines that would make the existing technology more reliable in practice (such as ensuring that batteries were always recharged). It was noticeable, however, that teams who used the laptops regularly seemed to deal with problems in a constructive way, rather than dismissing the technology as unworkable.

The other major reason for non-usage was not necessarily that teams perceived no benefit from using the laptops, but that influential members preferred other ward round practices (such as sitting ward rounds or walking ward rounds supported by paper notes).

Interestingly, the architecture of the building appeared to influence laptop usage, as all teams based on the upper floor were users, while those on the lower floor were, at best, irregular users. This may be due to other factors and interview data showed it was not always the rule, but it seemed that the particular way the laptops were set up made carrying them upstairs especially cumbersome. The department practice of teams being assigned specific machines meant they kept them in their (often locked) offices; 
this, in turn, often prevented teams visiting a different floor from using the laptops available there.

The study was not able to find any measurable data on the effects of using wireless laptops on ward rounds, nor did users have access to such evidence. Rather, individuals held particular beliefs about the benefits (or otherwise) of laptop use. Thus both users and nonusers agreed that laptops could provide better data access and the possibility of immediate and supervised order entry. Three types of data that could be accessed were identified: standard data that an Intern/medical student might forget to present, or present incorrectly; timely data, for instance, the latest lab results; and data that would not normally be expected to be required (or necessarily available), such as a full medical history or recent research findings relevant to a particular case. Access to the latter two types, at the bedside, was seen to be a distinctive contribution of MICT use.

Users and nonusers differed, however, in whether they believed that such data were beneficial for medical education, patient care, or the efficiency of their work. This may relate to different views on the use of data in ward rounds. Thus nonusers tended to believe that the laptops made too much data available on ward rounds and encouraged doctors to rely on them rather than developing their own judgement beforehand. This was seen as making decision-making more variable and plan-formulation more contingent by emphasizing immediacy and creating more interruptions and distractions. As a result, in these doctors' opinion, data analysis and synthesis before the round was reduced, and decisions became less consistent and considered, to the detriment of junior doctors' education. For the multi-task users, on the other hand, the data-intensive environment created by the laptops enabled better team discussion and decision-making, leading to more concrete and immediately implemented care plans, and more effective education.

From the nonusers' perspective, clinical decision-making involved the considered evaluation of available data and the preformulation of an appropriate treatment plan that could be revised in the light of collegial debate or significantly discrepant evidence of the patient's condition. Hence students needed to be trained in presenting and defending their assessment of the available data. Enthusiastic laptop users, however, saw decisionmaking as a more collective process involving real-time data analysis leading to the immediate implementation of appropriate treatment. Hence students needed to learn to access and integrate data quickly from many sources and to take prompt action.

Some other, less important, reasons for use included caseload, especially in peak periods or when one team was temporarily looking after another's patients (because this made it difficult to recall every patient) and the extent to which individual patients' results might be updated during the course of ward round. The latter would, of course, depend on the duration of the ward round which could vary from one Attending to another.

The personal style of senior doctors appeared to influence usage significantly by determining the type of ward round (walking or sitting) and their willingness to instigate a change of practice, especially in a situation of high team membership turnover. The senior doctors' attitudes to technology, however, seemed to relate more to how the laptops were used than with if they were used or not. These findings are summarized in Table 1. 
Table 1. Influences on Laptop Use for Ward Rounds

\begin{tabular}{|c|c|}
\hline $\begin{array}{l}\text { No association } \\
\text { with use or non- } \\
\text { use }\end{array}$ & $\begin{array}{l}\text { - Age } \\
\text { - Gender } \\
\text { - Seniority } \\
\text { - Use of desktop technology/Internet } \\
\text { - Previous experience } \\
\text { - Team size } \\
\text { - Availability of desktop computing } \\
\text { - Availability of full EMR on the laptops }\end{array}$ \\
\hline $\begin{array}{l}\text { Some association } \\
\text { with } \\
\text { non-usage }\end{array}$ & $\begin{array}{l}\text { - Unreliability of technology } \\
\text { - Building layout } \\
\text { - Sevice characteristics } \\
\text { practices } \\
\text { - Senior doctors' preference for decision-making with data } \\
\text { available before the round } \\
\text { - Senior doctors' belief that junior doctors need to be able to } \\
\text { present and defend their decisions } \\
\text { - Senior doctors' concern about distraction of junior doctors } \\
\text { during ward round } \\
\text { - Sitting ward round }\end{array}$ \\
\hline $\begin{array}{l}\text { Some association } \\
\text { with usage }\end{array}$ & $\begin{array}{l}\text { - Senior doctors' belief in the benefits of laptop use } \\
\text { - Senior doctors' willingness to instigate new practices } \\
\text { - High case load } \\
\text { - Senior doctors' perception of benefits of rich data } \\
\text { availability for education and decision-making } \\
\text { - Senior doctors' perception of need for timely data and } \\
\text { action } \\
\text { - Senior doctors' belief in collective, real-time decision- } \\
\text { making }\end{array}$ \\
\hline $\begin{array}{l}\text { Association with } \\
\text { both usage and } \\
\text { non-usage }\end{array}$ & - Walking ward round \\
\hline
\end{tabular}

\section{DISCUSSION}

In contrast to findings of other studies, it appeared that characteristics such as age, gender, and seniority did not seem to influence MICT device use. This may be because all users were highly skilled professicnals working in an IT-intensive setting and where senior doctors, especially, had many years experience of EMR use.

This case also suggests that, contrary to suggestions in the literature, the benefits of MICT use in ward rounds were not self-evident and a significant proportion of doctors did not use the laptops at all. While the immaturity (and hence unreliability) of 
the technology was widely cited as a reason for non-use, this can, at best, only partly explain such behavior as a number of doctors used the laptops regularly despite this.

Five points, in particular, may be relevant to understanding this situation. First, it seems that all ward rounds are not equal: they are not the uniform, highly mobile practice suggested by some advocates of MICT use. Sitting ward rounds, for example, would seem well supported by desktop computers. Second, doctors appeared to have different perceptions of the function of ward rounds (for example decision-making with available data and testing of junior doctors' presentations or collective decision-making moments with all possible data) and whether this could be supported by MICT. Third, doctors' attitudes varied toward technology, but also regarding the importance of rich and timely data in clinical decision-making, the effectiveness of existing practices, and their willingness to change practices. Fourth, the costs and benefits of MICT use were necessarily based on individual perceptions as measurable evidence was lacking. So, while some reasons for non-use, such as device reliability or the inconvenience of carrying the laptop upstairs, may not have been as serious as they were said to be, without strong evidence of benefits, even small costs may be enough to discourage use. As the enthusiastic laptop users also showed, individuals could often do something about the situation, such as pressuring for better hardware maintenance. Fifth, strong social influences, such as the power relationships between grades of doctors, existing work routines, team dynamics, and department practices such as on device sharing, shaped laptop usage and were also influenced by it.

Local circumstances seemed to play an additional role. High staff turnover, for example, meant that training needs were high and continuous but also that using laptops on ward rounds provided an important opportunity for sharing of experience on EMR use. Similarly, the hospital architecture, combined with specific device characteristics, caused problems for even the most enthusiastic users. Thus the particular pattern of MICT adoption would seem likely to vary even among apparently similar settings.

The influence of hospital architecture also illustrates how, even though the laptops themselves may have been highly mobile, by attaching them to trolleys to enable them to be used by a doctor who would normally be standing during a ward round, their effective mobility was reduced (indeed this restriction was, in part, a deliberate strategy by the hospital to reduce the risk of the laptops being stolen). Even without the trolley, the ubiquitous use of the laptops was constrained by their battery life. Mobility of the device itself is, therefore, not necessarily the same as its mobility in practice.

Finally, the findings emphasise the active role of users in the adoption of MICT devices. This operates in a variety of ways, from their perceptions of the costs and benefits of wider availability of information to their willingness to change routines to accommodate device usage. This would seem particularly the case in the current state of MICT use, where individual users' access to mobile, computer-based resources is often dependent on whether they bring the devices to the work setting themselves. Moreover, if the purpose of MICT use is seen to be the provision of ubiquitous information resources, rather than devices per se, then users may feel that their needs are adequately met by static devices, providing these are sufficiently numerous and available, without needing to have the device at the exact point of use. Ubiquity may, therefore, be seen not as an objective characteristic of a technological resource, but as dependent also on users' perceptions. 


\section{CONCLUSION}

While the findings reported here relate to only one site and one type of MICT use, evidence from other sites in our study suggests that they raise common issues that may extend beyond the particular medical setting studied. Recognising, for example, the variability of apparently standard work practices, the importance of individual perceptions (and the social processes influencing them), the role of established organizational routines, and the way in which these are shaped by, and shape, work practices would seem relevant in other contexts.

Thus, while it may, as the call for papers for this conference proposes, increasingly be "possible to create ubiquitous information[-rich] environments [that provide] new possibilities and opportunities for organizations to improve their productivity and effectiveness," the evidence presented suggests that these possibilities do not arise automatically or instantly. Moreover, perhaps especially in the context of current attempts to provide such environments through mobile devices, the realization of these possibilities appears to be subject to significant social influences. Even if some technical, architectural, and policy barriers to MICT use may be overcome in time, therefore, without clear evidence of unequivocal benefits, adoption will rely on users' beliefs about the value of ubiquitous information. It would appear, moreover, that such beliefs cannot be assumed to be universally positive. Whether this reflects the persistence of social influences that may be expected to diminish as the opportunities provided by MICTs achieve greater recognition, or represents an enduring alternative understanding of particular work practices, however, remains to be seen.

\section{ACKNOWLEDGMENTS}

Funding for this research was received from Fundação para a Ciência e Tecnologia, Lisbon, and St. Edmunds College, Cambridge. The support of Dr. David Nashel and all his staff at the VA Medical Center is gratefully acknowledged. This study received IRB approval (Protocol 00882).

\section{REFERENCES}

Atkinson, P. The Clinical Experience, London: Gower, 1981.

Bardram, J., Kjær, T. A. K., and Nielsen, C. "Supporting Local Mobility in Healthcare by Application Roaming among Heterogeneous Devices," in Proceedings of the Fifth International Conference on Human Computer Interaction with Mobile Devices and Services (Mobile $\mathrm{HCI}^{\prime} 03$ ), Berlin: Springer Verlag, 2003 (available online at http:/ www.daimi.au.dk/ bardram/docs/mobile_HCl.pdf).

Barret, J. R., Strayer, S. M., and Schubart, J. R. "Assessing Medical Residents' Usage and Perceived Needs for Personal Digital Assistants," Internctional Journal of Medical Informatics (73:1), 2004, pp. 25-34..

Cox, J. "Wireless Woos Doctors: Networked Mobile Devices Help Improve Patient Care and Diagnosis," Network World Fusion, December 9, 2002 (available online at http:/ www.nwfusion.com/research/2002/1209sector.html). 
Davis, G. B. "Anytime/Anyplace Computing and the Future of Knowledge Work," Communications of the ACM(45:12), 2002, pp. 67-73.

Esbjörnsson, M. "Mobile Reporting: Supporting Road Inspectors," in Proceedings of Interact'01-IFIP TC 13 International Conference on Human-Computer Interaction, Amsterdam: IOS Press, 200, pp. 747-748 (available online at http:/www.tii.se/ mobility/publications.htm).

Esbjörnsson, M., Juhlin, O., and Östergren, M. "Making Motor Bikers Come Together-Fast Moving Users and Mobile Ad Hoc Networks," in Proceedings of $25^{\text {th }}$ Information Systems Research Seminar in Scandinavia, Bautahøj, Denmark, 2002.

Esbjörnsson, M., and Östergren, M. "Hocman: Supporting Mobile Group Collaboration," in Extended Abstracts of the Conference on Human Factors in Computing Systems, New York: ACM Press, 2002, pp. 838-839 (available online at http://www.tii.se/mobility/ Files/Hocmanpaper.pdf).

Freeman, H. E., and Reeder, L. G. "Medical Sociology: A Review of the Literature," American Sociological Review (22:1), 1957, pp. 73-81.

Glaser, B. G., and Strauss, A. L. The Discovery of Grounded Theory: Strategies for Qualitative Research, New York: Aldine, 1967.

Grasso, B. C., and Genest, R. "Use of a Personal Digital Assistant in Reducing Medication Error Rates," Psychiatric Services (52:7), 2001, pp. 883-884, 886.

Holleran, K., Pappas, J., Lou, H., Rubalcaba, P., Lee, R., Clay, S., Cutone, J., Flammini, S., Kuperman, G., and Middleton, B. "Mobile Technology in a Clinical Setting," in Proceedings of the AMIA Annual Fall Symposium, 2003, p. 863.

Kelly, J. "Going Wireless," Hospital Health Networks (74:11), 2001, pp. 65-66, 68.

Martins, H. M. G., and Jones, M. R. "What's So Different about Mobile Information Communication Technologies (MICT) for Clinical Work Practices: A Review of Selected Pilot Studies," Health Informatics Journal (forthcoming).

McLeod, T. G., Ebbert, J. O., and Lymp, J. F. "Survey Assessment of Personal Digital Assistant Use among Trainees and Attending Physicians," Journal of American Medical Association (10:6), 2003, pp. 605-607.

Strauss, A. L., Shizuko, F., Suczek, B., and Wiener, C. Social Organization of Medical Work, New Brunswick, NJ: Transaction Publisher, 1997.

Zuboff, S. In the Age of the Smart Machine, New York: Basic Books, 1987.

\section{ABOUT THE AUTHORS}

Henrqiue M. G. Martins is a medical doctor and holds a Master's in Management Studies. $\mathrm{He}$ is finishing a Ph.D. at the University of Cambridge, working within the Information Management area on the topic "The Use of Mobile Information and Communication Technologies in Clinical Settings." His interests are the interface between the areas of medicine and management, namely mobile clinical information systems, as well as management education to medical students and junior doctors. He has presented work in several conferences and has some forthcoming publications in these areas. Henrique can be reached at hmgm2@cam.ac.uk.

Matthew R. Jones is a University Lecturer in Information Management in the Department ci Engineering and the Judge Institute of Management at the University of Cambridge. His research interests concern the relationship between information systems and social and organizational change. He has published widely in this area, including several studies in the healthcare domain. Matthew can be reached at mrj10@cam.ac.uk. 